\title{
From pharmacy faculty to pharmacy shop: still a logical pathway in Europe?
}

\author{
Livio Garattini ${ }^{1} \cdot$ Anna Padula $^{1}$
}

Published online: 26 December 2017

(C) Springer International Publishing AG, part of Springer Nature 2017

\section{Introduction}

Until fairly late in the last millennium, pharmacists used to apply their scientific skills to make, compound and dispense drugs, but these roles have substantially diminished over time. Nowadays, community pharmacies have definitively lost the task of manufacturing medicines, but they still dispense drugs, with this now being a major activity [1]. In the long run, this shift has somehow altered the balance between the historical combination of pharmacy qualifications and running a shop.

Here we discuss whether pharmacy education in the EU is still consistent with practice in the community, where the vast majority of pharmacy graduates still work; community pharmacists, after physicians and nurses, are the third largest group of healthcare professionals [2].

After a brief overview of the EU regulations for pharmacy education and a background to the 'state of the art' in the main Western European countries, we offer a tentative proposal, open to debate.

\section{European framework}

Pharmacy education in the EU should have been harmonized by two general documents that concern academic education. The EU Directive 2005/36 [3] (subsequently

Livio Garattini

livio.garattini@marionegri.it

1 CESAV, Centre for Health Economics, IRCCS Institute for Pharmacological Research "Mario Negri”, 24020 Ranica, Italy amended by the EU 2013/55) is the official text for the mutual recognition of qualifications to permit free movement of professionals among member states. For community pharmacists, it states that they should train for at least 5 years, including 4 years at university and 6 months of training in a community pharmacy.

The Bologna Declaration of 1999 [4] (updated in Berlin in 2003), co-signed by all the European Ministers of Education, is a previous document aimed at harmonizing university degrees and thus at promoting professionals' mobility and academic cooperation throughout the EU. This declaration described a three-tier graduation (the 'Bologna model') for all faculties after secondary education: (1) bachelor (3 years), (2) master (2 years), and (3) doctorate (generally three further years).

However, the two documents do not necessarily lead to a single model for pharmacy education, since the EU Directive specifies a seamless 5-year course, while the 'Bologna model' implies a bachelor course to start with, presumably to prepare graduates for entering the job market or continuing their education with master programs.

According to a survey conducted by the 'Pharmacy Education in Europe' (PHARMINE) consortium in 2011 [5], whose main aim was to assess whether pharmacy education was still appropriate to pharmacy practice in the EU, the regulation is still piecemeal and fragmented throughout the EU countries. Focusing on the older Western EU member states, the years required for minimum graduation still vary a lot from one country to another (Fig. 1). For instance, French and Dutch pharmacists are trained at least for 6 years (including 6 months of training in a community pharmacy for students choosing that career path), regardless of their future setting and role. However, 


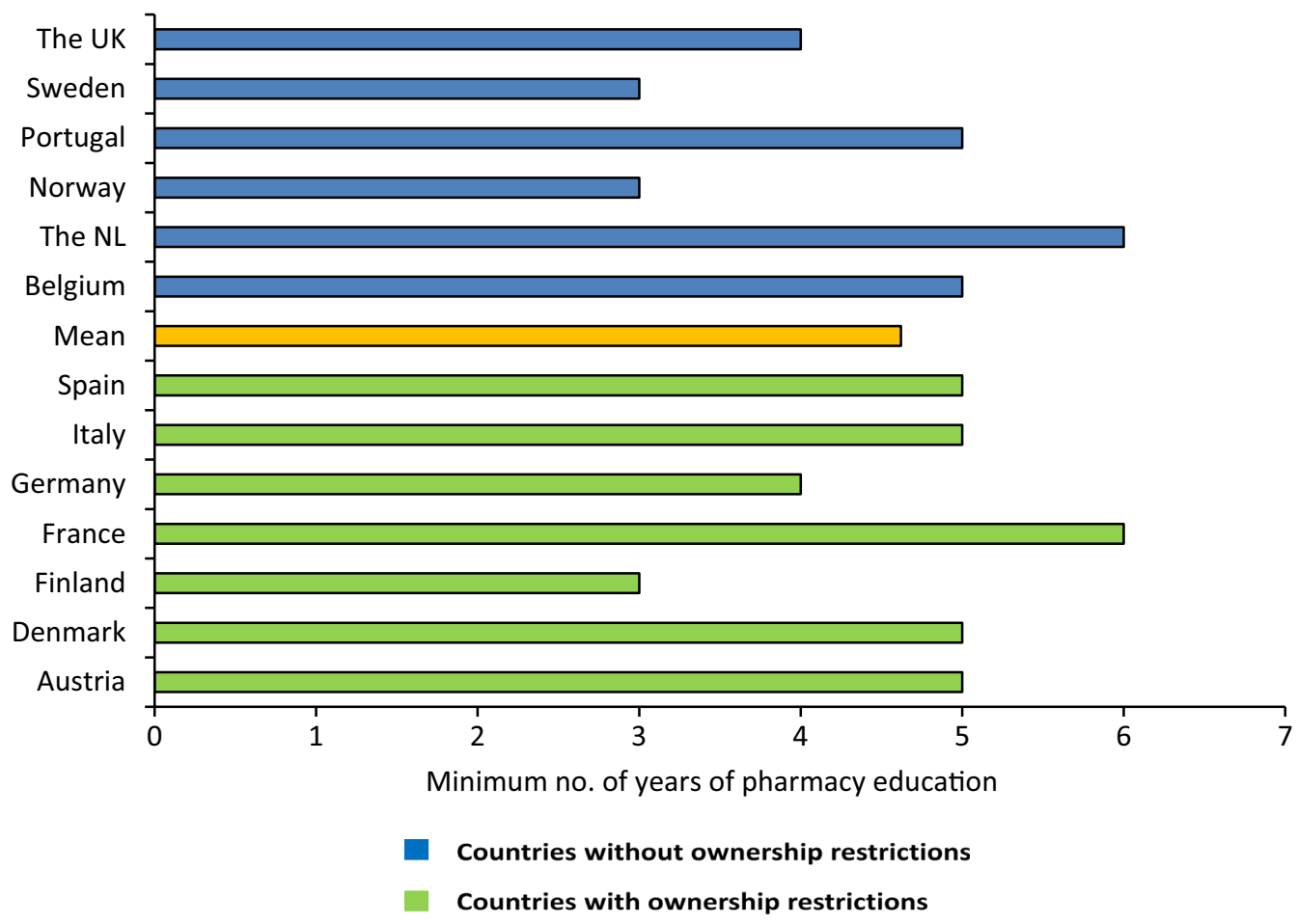

Fig. 1 MInimum duration of pharmacy training in the main western European countries [12]

while French community pharmacists are responsible only for checking prescriptions and thus are not allowed to alter the dosage or stop a treatment without consulting the prescribing doctor (except for emergency reasons) [6], Dutch community pharmacists are legally and professionally responsible for optimizing drug prescriptions [7]. This means they can intervene if a prescription does not respect national guidelines or does not seem suitable for an individual patient. In France, almost three quarters of the members of the national College of Pharmacists still worked in community pharmacies in 2007 , and more than half of them were pharmacy owners, while in the Netherlands, pharmacy ownership is not restricted to pharmacists.

Prior to application for registration as a community pharmacist, a British student must first successfully complete a 4-year degree program and then a compulsory 1 -year post graduate training, including at least 6 months in a community pharmacy [8].

Three Scandinavian countries (Sweden, Norway and Finland) are the only ones in which a 3-year bachelor degree is necessary first (in line with the 'Bologna model'), followed by a 2-year master's degree. For instance, in Finland, bachelor graduates in pharmacy are eligible to practice as community pharmacists and fully responsible for drug dispensing and patient counseling, but only pharmacists with a master's degree can own a community pharmacy [9]. An essential part of the bachelor degree in Finland is a mandatory 6-month internship in a community pharmacy, during which trainees receive monthly wage of $\approx € 1000$ [10].

Finally, Italy is the only mainland European country where pharmacy education has been recently lengthenedfrom 4 to 5 years in the 1990s [11].

In summary, the EU directive appears to have influenced the patterns of pharmacy graduation in Western Europe to a larger extent than the Bologna declaration [12].

\section{Critical issues}

The combination of pharmacy university graduation and community chemist's shop seems to have found a wide range of uneven and heterogeneous solutions throughout the Western European countries at present. While the ownership of community pharmacies is still mainly limited to pharmacists in the largest mainland countries (France, Germany Italy and Spain) [1], the minimum duration of their graduation varies from 3 to 6 years. The most noticeable combination is Finland, where a pharmacist can graduate with a bachelor's degree after 3 years and work in a community pharmacy, but a 5-year master's degree is needed to own the shop [5]. Among the subsample of countries still restricting ownership to pharmacists, Finland is also the only one that has a minimum pharmacy degree length below the overall average of Western European nations.

Today the health service provided by pharmacists can potentially vary from merely checking prescriptions and 
then dispensing drugs [6], to even to independently prescribing medicines after a basic clinical diagnosis [8]. While the former requires basic pharmaceutical knowledge for dispensing and counseling, the latter, of course, calls for much deeper scientific knowledge with, ideally, even some level of specialization in a clinical area of expertise (e.g. cardiology, neurology, oncology, etc.). In most countries the pharmacist's role as employee in a community pharmacy seems closer to the lower part of the range, partly because pharmacists always have a potential 'conflict of interest' when employed in a private pharmacy, on account of their dual role of health professional and commercial agent [13]. Since private pharmacies are still predominant in almost all European healthcare systems, regardless of whether they are owned by a single pharmacist or a large company, a minimum of 3 years before graduation could be a reasonable solution for a pharmacist to start working in a pharmacy shop, consistently with the 'Bologna model'. An alternative might be to devolve the supply and dispensing of drugs to registered pharmacy technicians, thus enabling community pharmacists to extend their clinical patient-centred role, more like what happens for other healthcare professionals (e.g. nurses vs physicians) [14]. However, this solution, envisaged in the UK and mainly stemming from the American experience, has aroused concern among British community pharmacists [15], who are reluctant to devolve their dispensing role to technicians. This reluctance might be even stronger in large mainland countries such as Italy, where graduated pharmacy technicians have never existed-possibly not by chance-and private pharmacies owned by (traditionally hereditary) single pharmacists still predominate, so any substantial change to the status quo is perceived as a potential 'Trojan horse' in favor of a real market 'liberalization' [1].

\section{Comment}

Pharmacists have strived over recent years to become increasingly clinical professionals in secondary care settings (typically hospitals), whereas they have lost traditional roles, such as drug 'manufacturing' in community pharmacies. In the light of these radical changes, it is time to reconsider their baseline education in the EU, especially for those working in community pharmacies, which, in most European countries, are still private shops where commercial considerations (obviously) prevail over public health tasks [13]. We think that a minimum of 3 years to earn a bachelor degree in pharmacy-such as exists in almost all faculties except medicine (human and veterinary) nowadays-would be a wise solution in the EU, making it easier for young pharmacists to enter their main 'labor market' with the essential knowledge to provide their basic health service of dispensing drugs professionally.

To conclude, the great weakness of the EU in this field, like some others, is that it has inherited a piecemeal framework at national level, but lacks the political strength to harmonize it, unfortunately often even adding further confusion through contradictory recommendations. However, we are still fiercely convinced that European solutions are potentially the best ones to overcome national selfishness backed by historically powerful lobbies. For instance, the Italian association of pharmacists who own pharmacies still opposes the dispensing of medicines (except for overthe-counter drugs) by pharmacists employed in para-pharmacies and health corners of large-scale retail outlets [1]. This professional struggle against fully 'peer professionals' can only be justified by the defense of a financial privilege [16].

We believe that in this perspective, it is time to (re)open the general debate.

Funding None declared.

Compliance with ethical standards

Conflict of interest None declared.

Ethical approval Not applicable.

\section{References}

1. Garattini L, van de Vooren K, Curto A. Will the reform of community pharmacies in Italy be of benefit to patients or the Italian National Health Service? Drugs Ther Perspect. 2012;28(11):23-6.

2. Mossialos E, Courtin E, Naci H, et al. From 'retailers' to health care providers: transforming the role of community pharmacists in chronic disease management. Health Policy. 2015;119:628-39.

3. Directive 2005/36/EC of the European Parliament and of the Council of 7 September 2005 on the recognition of professional qualifications. Official Journal of the European Union. 2005 Sep 30.

4. The Bologna Declaration of 19 June 1999: joint declaration of the European Ministers of Education. https://www.eurashe.eu/ library/bologna_1999_bologna-declaration-pdf/. Accessed 2017 Oct 10.

5. Atkinson J, Rombaut B. The 2011 PHARMINE report on pharmacy and pharmacy education in the European Union. Pharm Pract (Granada). 2011;9(4):169-87.

6. Bourdon O, Ekeland C, Brion F. Pharmacy education in France. Am J Pharm Educ. 2008;72(6):132.

7. Teichert M, Schoenmakers T, Kylstra N, et al. Quality indicators for pharmaceutical care: a comprehensive set with national scores for Dutch community pharmacies. Int $\mathbf{J}$ Clin Pharm. 2016;38(4):870-9.

8. Sosabowski M, Gard P. Pharmacy education in the United Kingdom. Am J Pharm Educ. 2008;72(6):130. 
9. Katajavuori N, Hakkarainen K, Kuosa T, et al. Curriculum reform in Finnish pharmacy education. Am $\mathrm{J}$ Pharm Educ. 2009;73(8):151.

10. Pitkä K, Löfhjelm U, Passi S, et al. Integrating internships with professional study in pharmacy education in Finland. Am J Pharm Educ. 2014;78(9):173.

11. Ministero dell'Istruzione dell'Università e della Ricerca. Determinazione delle classi di laurea magistrale. Decreto Ministeriale 16 marzo 2007. GU 9 luglio 2007 n. 155.

12. Atkinson J, Rombaut B. The PHARMINE study on the impact of the European Union directive on sectoral professions and of the Bologna declaration on pharmacy education in Europe. Pharm Pract (Granada). 2011;9(4):188-94.
13. Garattini L, Padula A. Pharmaceutical care in Italy and other European countries: between care and commerce? Postgrad Med. 2017. https://doi.org/10.1080/00325481.2018.1399043 (Epub 2017).

14. Waterfield J. Is pharmacy a knowledge-based profession? Am J Pharm Educ. 2010;74(3):50.

15. Schafheutle EI, Jee SD, Willis SC. Fitness for purpose of pharmacy technician education and training: the case of Great Britain. Res Social Adm Pharm. 2017;13(1):88-97.

16. Santuari A. Legal and organisational innovation in the Italian pharmacy system: commercial vs public interest. Health Econ Policy Law. 2017;12(4):495-513. 